\title{
Erratum to: Percutaneous closure of atrial septal defect via transjugular approach with Blockaid device in a patient with interrupted inferior vena cava
}

\author{
Rao D. Seshagiri $\cdot$ A. N. Patnaik $\cdot$ B. Srinivas
}

Published online: 28 September 2012

(C) Japanese Association of Cardiovascular Intervention and Therapeutics 2012

Erratum to: Cardiovasc Interv and Ther

DOI 10.1007/s12928-012-0113-4

The 4th sentence of the "Discussion" section appears incorrectly as a result of a typographical error by the publisher. The sentence should read as follows:

Congenital obstruction may be due to a membrane or interruption with azygos continuation [2].

The online version of the original article can be found under doi:10.1007/s12928-012-0113-4.

R. D. Seshagiri · A. N. Patnaik · B. Srinivas $(\bowtie)$

Department of Cardiology, Nizam's Institute of Medical

Sciences, Hyderabad 500 082, Andhra Pradesh, India

e-mail: srinivas_bh2005@yahoo.com 